This is an electronic reprint of the original article. This reprint may differ from the original in pagination and typographic detail.

Author(s): Rönkä, Anna; Sevón, Eija; Räikkönen, Eija; Hintikka, Timo

Title: $\quad$ You have a Message from Illi! : The Mobile Diary in Researching Children's Daily Experiences

Year: $\quad 2017$

Version:

Please cite the original version:

Rönkä, A., Sevón, E., Räikkönen, E., \& Hintikka, T. (2017). You have a Message from Illi! : The Mobile Diary in Researching Children's Daily Experiences. Child Indicators Research, 10(2), 505-523. https://doi.org/10.1007/s12187-016-9386-y

All material supplied via JYX is protected by copyright and other intellectual property rights, and duplication or sale of all or part of any of the repository collections is not permitted, except that material may be duplicated by you for your research use or educational purposes in electronic or print form. You must obtain permission for any other use. Electronic or print copies may not be offered, whether for sale or otherwise to anyone who is not an authorised user. 
Manuscript: You have a message from Illi! The mobile diary in researching children’s daily experiences

Anna Rönkä 1, Eija Sevón 1, Eija Räikkönen 2 \& Timo Hintikka

1 Department of Education, University of Jyvaskyla, P.O.Box 35, 40014 Jyvaskyla, Finland 2 Faculty of Education, University of Jyvaskyla, P.O.Box 35, 40014 Jyvaskyla 3 School of Health and Social Studies, JAMK University of Applied Sciences, Jyväskylä 


\begin{abstract}
Thus far, daily diary studies have mostly focused on adults and adolescents, while only a few have researched young children. In this methodological article, we introduce and evaluate a mobile diary application, "You have a message from Illi”, designed to capture young, under-school-age children's daily experiences at home and in day care, in the context of a 24h economy where parents work nonstandard hours and child care is arranged accordingly. We also compare childrens' mood ratings reported by both the children themselves and adults. Children recruited either from day care centers $(\mathrm{N}=15)$ or day and night and care centers $(\mathrm{N}=17)$ carried smartphones with them for one week and reported their daily moods and activities three times a day by mobile phone as motivated by "Illi”, a fairy-tale character. The questions concerned daily activities, moods and transitions as well as good and challenging moments. The study demonstrated children's ability and motivation to participate in a mobile diary and produce valuable information about their daily lives. The method captured fluctuations in children's daily moods, as reported by both children and adults. The mood evaluations of adults and the children themselves correlated. Parents and day care staff perceived participation in the mobile diary study as practical, relevant and not overdemanding, and that the method was easy to integrate into daily life.

Keywords: diary method, mobile application, young children, daily family life, 24h-economy, day care
\end{abstract}




\section{You have a message from Illi! The mobile diary in researching children's daily experiences}

Technological progression in high-tech and mobile tools has opened up several novel possibilities for data collection. Technology-assisted tools are especially useful in diary studies, where answers are frequently required and which take place in everyday settings Diary methods and the tools used in them are currently under rapid development (Intille 2012; Malinen, Rönkä and Sevón 2015). The paper-and-pencil method has been replaced, or at least complemented, by a variety of new technological tools for experience sampling, such as pagers (Larson 1989), mobile phones (Plowman and Stevenson 2012; Malinen, Rönkä, Tolvanen, Sevón and Jokinen 2015; Rönkä, Malinen, Kinnunen, Tolvanen and Lämsä 2010), palmtops (Perrez, Schöbi and Wilhelm 2000), Pda’s (Whalen et al. 2006ab) and handheld computers (Connelly and Bickel 2011). However, to date diary studies have mostly focused on adults and adolescents, while only a small minority has researched young children. In this article, we introduce a mobile diary application especially developed for collecting data from young, pre-literate children and from their carers at home and in day care. We also describe how the data collection was arranged and discuss different approaches to the analysis of mobile diary data. Furthermore, the method and the quality of the data gathered are evaluated.

\section{Children's daily life in a 24h economy}

The specific context of the study is the so called $24 \mathrm{~h}$ economy that is a society where services are open round the clock and where large groups of employees have to work outside traditional office hours (e.g., Presser 2003; Strazdins, Korda, Lim, Broom and D’Souza 2004). For families with children, this means that their parents might have to work evenings, weekends or nights, and special arrangements made for childcare during these hours. According to earlier research, the effects of parental non-standard working time on children can be either positive or negative. For some 
children whose parents work nonstandard hours, possible benefits include enjoying more time with their parents, as parents may take turns in work, parenting and child care (Li et al. 2014; Mills and Täht 2010). The negative aspects from child's point of view stem from parental fatigue due to working nights, difficulties in creating and maintaining family routines, lack of family time and greater unpredictability in daily life (Gassman-Pines 2011; Hsuch and Yoshikawa 2007; Strazdins et al. 2004). If parents work nonstandard hours, their children will need care also during these hours, which may present a problem if such care is not available or is discontinuous.

In Finland, formal childcare for children under school age is guaranteed by law and it is not restricted to standard office hours (Finnish Ministry of Social Affairs and Health 2013). The opening hours for formal childcare vary from the normal day (7am to $5 \mathrm{pm}$ ) to extended hours and 24/7 childcare, also known as “day and night care”. Currently, about 7\% of Finnish children under school age attend day and night care because either their parents or lone parent work nonstandard hours (Säkkinen and Kuoppala 2011) Although flexible daycare is provided in many countries (Halfon \& Friendly 2015; Jordan 2008; Statham \& Mooney 2003), Finland is one of the few that provide systematic, centre-based day and night care (Verhoef, Tammelin, May, Rönkä \& Roeters 2015).

The voices of children in day and night care have rarely been studied, although nonstandard care hours and parental working time patterns may affect these children's lives in many ways. By means of a specially designed mobile diary application we aimed to capture children’s daily experiences in relation to family and day care in a $24 \mathrm{~h}$ economy. The children in this study were recruited either from traditional day care centers, which are open only during the day time and weekdays, or from day and night care centers that offer childcare also during evenings, early mornings, weekends and nights. 


\section{Daily diary approach}

Diary methods have become popular as a data collection method in the social and behavioral sciences (Intille 2012). In diary studies, participants give frequent reports on their experiences; typically, this means answering either once or several times a day over a period of one or two weeks (see Bolger, Davis and Rafaeli 2003). Such an approach allows researchers to study short-lived events, transitions and daily and weekly variation in moods and interactions. The diary method is especially suited to the study of daily family dynamics, which is known to include tensions and fluctuations (Laurenceau and Bolger 2005; Rönkä et al. 2010; Sevón, Malinen and Rönkä 2014). As answering takes place in close proximity to the events of interest, the diary method is able to obtain memory-unbiased, situation-specific information on everyday situations and moments, making it possible to capture life as it is lived (Larson and Almeida 1999; Delle Fave and Massimini 2004). In research focusing on daily family life, the diary method makes it possible to study all the family members at the same time and thus attend to their individual points of view. Aside from the family context, diary methods have also been used in the contexts of work, classroom environment and leisure time (e.g. Larson 1989). Owing to their easy portability, diary booklets or devices are well suited to the analysis of everyday life, where people frequently move between home, workplace, school and day care. When applied in the context of the 24h economy, we expected that the diary method would be able to make varying daily and weekly schedules and rhythms visible and enable access to daily transitions and emotions.

\section{Diary studies among children and adolescents}

Although most diary studies have been conducted among adults, diaries have also increasingly been used among adolescents and school-aged children to obtain reports on their daily activities, moods and interactions (Larson 1989; Whalen et al. 2006ab). Our theoretical and epistemological starting point and the leading motive for this study was our belief in the ability of young children to produce 
knowledge about their everyday lives and to participate in research. The views of young, underschool-aged children have been little studied, probably due to the assumption that conducting research with young children as participants is difficult (see Clark 2005; Cremin and Slatter 2004). Childhood studies emphasise that children's voices need to be respected and heard in matters concerning their lives and that children need to become active participants in society (Gallagher and Gallagher 2008; Powell and Smith 2009). In recent research, children’s capacities for understanding have been re-evaluated in many respects and new methodological tools developed for research specifically with children (Clark 2005; Darbyshire, MacDougall and Schiller 2005; Einarsdóttir 2007; Morrow 2005). It is nowadays acknowledged that young, pre-literate children can benefit from the use of multiple methodological tools that take into account the differences between children and children's ways of perceiving the world (Clark 2005).

Larson (1989) was among the first to examine daily experiences and time use in preadolescents aged 10 to 14 . The pre-adolescents carried electronic pagers which prompted them to give written reports in special booklets about their current activities and moods. In the study by Whalen and colleagues (2006ab), school-aged children (mean age 11 years) reported their moods, behaviors and activities by using electronic PDA diaries. The study compared two groups of children, those with and those without diagnosed ADHD, and also collected mothers' ratings and interpretations of their children's daily behavior and interaction. According to the maternal reports (Whalen at al. 2006b), it was the preparatory tasks of daily living that were experienced as especially challenging in the families of children diagnosed ADHD. These preparatory tasks, for example in the mornings, were linked disproportionately to child behavior problems, parental negative affect, and contentious interactions. The children's self-ratings also revealed situational effects, indicating that school-age children with ADHD can give meaningful self-reports when issued with carefully structured electronic diaries. Connelly and Bickel (2011) used handheld computers as tools in a two-week diary study on the daily factors related to children's headache. 
Children $(\mathrm{N}=28)$ aged 8-17 who suffered from primary headache used electronic diaries to record headache occurrence, various stressors and their daily health behavior.

The diary method has proven well suited for investigating the daily lives of adolescents. Rönkä and her colleagues (2010) piloted a mobile diary in a group of adolescents aged 11-17. They found that mobile phones were user-friendly and attractive devices for adolescents, and highly appropriate for the study of daily interaction and moods (see also Malinen et al. 2015). Likewise, Matthews, Doherty, Sharry and Fitzpatrick (2008) found mobile phones an effective platform for recording adolescents' daily moods. They found that adolescents were more likely to complete a mood diary presented on a mobile phone than when a similar diary was presented as a paper chart. The mobile phone diary provided adolescents with sufficient privacy, was costeffective, user-friendly and client-centered.

Diary methods have, however, seldom been used with younger children, especially among children who cannot yet read or write. While some diary studies have been conducted with young children, the informants have been adults, such as parents or day-care personnel, rather than the children themselves. For example, Plowman and Stevenson (2012) used mobile phone diaries to study everyday life among children aged 3 to 4 . Since their focus was on very young children, their parents participated in collecting the data where this involved taking photographs and reporting daily activities via text messages. Plowman and Stevenson's study showed that a mobile diary, as used in their study, was easy to integrate into the daily life of families. Lämsä, Rönkä, Poikonen and Malinen (2012), in turn, developed a child diary to systemically collect observations by parents and day care personnel on children's daily interactions and moods at home and in day care. The children in their paper-and-pencil diary study were aged 1 to 6 years and they were invited to draw or tell stories about their daily life on their own pages in the diary. The results shed light on weekly and daily rhythms, which cannot be captured by other methods, such as interviewing. Home was the place for the emotional expression of negative mood; the children expressed negative emotions 
most frequently at home and boys experienced negative mood more often than girls. However, the children's moods were generally rated as very positive. Although many participants found the diary study week interesting, many complained that it was time-consuming, and for a few adults even burdensome.

\section{Aims of the study}

The first, methodological, aim of this study was to illustrate and evaluate the development and use of a mobile diary in studying the daily life of young children in the context of a $24 \mathrm{~h}$ economy and round-the-clock child care. We demonstrate the different data collection phases through a smartphone application for children. The second aim of the study was to describe and compare data gathered from children and adults on children's daily moods. We explored the daily fluctuation in moods to find out to what extent the children's and adults' evaluations were congruent. Third, we analyzed the feedback received from children, parents and day care personnel to determine the strengths and limitations of the method.

\section{Method}

\section{Sample and context of the study}

"You have a message from Illi!” was a mobile diary study of 32 children and their carers. The children, along with their parents and day care personnel, were recruited to the study via day care and day and night care centers as part of two larger research projects. The mobile diary study was a collaborative component of these two multi-method research projects. The first, larger scale, project is titled xxxxxxxxxxxx, led by Author 1 and funded by the Academy of Finland. The data collection of the project consists of a cross-cultural survey (Finland, NL, UK) of parents of families with children under 13 years, parental interviews and a survey of, and interviews with, night and day care personnel. In addition, children’s perspectives were mapped with the present daily mobile 
diary, observation data and a specific story-telling method. The second project was Author's 2 postdoctoral research project $x x x x x x x x x x x$, funded by the Academy of Finland, in which the aim was to find out, from the perspectives of the different family members, especially young children (from 4 to 6 years), what kind of daily family life is satisfying. Special emphasis was placed on daily actions, interactions, emotions and their transmission within the family. In addition to the diary study, paper-and-pencil diaries, interviews, drawings, storytelling and photographing were also utilized to collect data within the families participating in this project.

A pioneering mobile diary technique for young children developed by Author 1 and Author 2 is the methodological dimension focused on here. Specifically, we evaluate the technique and its potential for enabling research participation among young, pre-school children. The use of purposive sampling facilitated a comparative analysis of children's experiences in family contexts characterized by one of two different working patterns: families where at least one parent worked standard hours $(n=15)$, and families where either both parents or a lone parent worked nonstandard hours $(n=17)$. All the parents of the children who were in day and night care worked nonstandard hours. The relevant background information on the families participating in the study is shown in Table 1. The children ranged in age from 4 to 6 years. Mothers were aged from 23 to 44 , and fathers from 30 to 44 . Comparison of the two groups showed that the proportion of non-intact families was higher among the children in day and night care than among the children in the day care group $(p=0.003)$. The reason for larger proportion of non-intact families in the day and night care group is because families are only eligible for a place in night and day care if either both parents or a lone parent work nonstandard hours. The data collection took place between April and September, 2012.

Insert Table 1 about here 


\section{Development of a mobile diary}

Our first aim in this article was to illustrate the development of a mobile diary application suitable for preschool-aged children and their caregivers. The mobile application had to be easy to use and attractive to children. With the help of the application children should be able to answer inquiries sent several times in the course of a day. Collecting daily diary data among young children who transit daily between home and day care poses several challenges. This particularly concerns children in day and night care, since their care times are unpredictable and fluctuating. Hence, daily questions and reporting times have to fit in with children's individualized daily schedules. Furthermore, the adults around these children vary, as both personnel and parents work in shifts, sometimes unpredictably. Children may have two homes instead of one. Therefore the diary application needs to be flexible to accommodate different family forms. Furthermore, the adults around these children (especially parents) may be very busy and tired as a result of shift work, at least during the evening, and therefore, reporting should not take too much time and energy. Our solution to the above-mentioned issues was to have the target children carry smartphones with them throughout the follow-up period. The diary data were collected in several waves by using smartphones owned by the project and loaned to the children. The cast of adults around the children (at home, in the care center), used the same application to report on the child's wellbeing. Mostly, we used structured questions, as these make reporting easier and less time consuming than the openended type questions. The children themselves answered questions specially formulated for them. By loaning the smartphones to the families, we ensured that all the target children would be able to participate irrespective of whether their parents had a new or older type of mobile phone.

\section{Diary procedure}

\section{Technical details}


The mobile application was developed in collaboration between two universities and an ICT company. An already existing web-program adapted for mobile devices was utilized and further developed (see Rönkä, Malinen, Jokinen and Häkkinen 2015). Android was chosen as the implementation platform. After platform selection, various mobile devices were compared and their feasibility for the purpose of the application and associated research was studied. Planning and implementation were processed in small steps and the functionality of each step tested with the help of prototypes. Alongside the mobile application design, an XML interface was implemented to help with communication between the backend application server and mobile application. The XML interface translated the messages between the two different systems: the server and the mobile application.

The present authors entered the names of the participants and programmed the timing of the diary questions using the web-platform. The child and his/her family used the mobile application which had been installed in the smartphone. Before the study, the application was piloted with seven children in order to ensure that children of that age are able to use the application and that the application works properly.

\section{Content of the diary questions and answering times}

In the application, a fairy-tale character named Illi helped the child to report daily moods and activities. There were questions for both adults and children. The answering times were in the morning, in the afternoon after lunch and nap time, and in the evening. Answering took place either at home or in the day care centre, depending on where the child was. At answering time, Illi sent the participants a reminder: "You have a message from Illi, a message from Illi”. The first question, which was addressed to the adult, asked for her or his immediate location ("Where are you at this moment?”). On the basis of the answer (at home, in day care) the questions concerned either the family or the day care context. Some of the questions were exactly the same in the two contexts, 
while others were context- and time-specific. The content and structure of the questions and measures is shown in Table 2. The questions, which were either structured or open-ended concerned, for example, the child's daily moods, activities, and both adult and peer contacts. The diary also dealt with daily transitions, key events and good and challenging moments.

Families were allowed four hours in which to answer Illi’s questions. If they had not answered after the first hour, the questions were sent again; this procedure was repeated three times. As the answers went directly to the web system, it was possible for the researchers to monitor the giving of answers in real time. If no answers were received, the family was contacted. Prior to the study, the participants were sent test questions to ensure that that the system functioned smoothly. Problems occurred in very few cases, and these were immediately solved. None of the participants dropped out while the number of missing answers was reasonable for an intensive diary study. Five children had no missing values in the emotion variables during the diary week. The mean percentage of missing values in the emotion variables was 11.04 ( $S D=0.56$; range 10.57-12.20).

Insert Table 2 about here

\section{The questions addressed to adults}

Adults’ perceptions of children’s moods, elicited three times a day, were studied with seven structured questions (see Table 2): Has the child been happy/sad/angry/ worried/ tired/restless/enthusiastic this morning/afternoon/evening? The responses were given on a scale from 1 (not at all) to 7 (extremely). Similarly, on each occasion, adults were asked about good and challenging moments (open-ended questions) and the quality of their interaction with the child (both structured and open-ended questions). In the morning two further questions were asked about where and how the child slept. The evening items targeted to home comprised structured questions on the family atmosphere, work-family interaction and the number of daily hassles, and an openended question on the parent's own mood. The questions targeted to day care concerned day care 
workers' perceptions of children's reactions to care and things that either pleased or irritated them.

\section{The questions for children}

After answering, the adult was instructed to give the mobile phone to the child. At that point, Illi greeted the child and said that it was the child's turn to answer. The questions addressed to the children concerned their daily moods, doings and interaction with their adult carers. The children's questions were spoken by Illi, and the child answered either by touching the relevant icons or by speaking and recording the answers.

Five questions concerned the children’s moods. Illi asked children, in a voice imitating the tone and intensity of the feeling: "Tell Illi in what kind of mood you have been this morning/afternoon/evening. Choose the picture of Illi's faces that suits you. Have you been happy (this morning)?” The responses were given on scale from 'not at all', to 'a little bit', 'somewhat', and 'really, really' and subsequently coded from one to four. The questions on whether the child had been angry, worried or tired were asked in the same way.

The open-ended questions asked by Illi concerned, for example, daily activities and good and challenging moments (see Table 2). The application had a recording function. Children answered to the open-ended questions by speaking and recording their answers. At day care in the evening, there were also yes-no statements on the child's interaction with adults. At the end of the session, Illi asked the child to give the mobile phone back to the adult, who was then instructed to send the answers. The answers were sent directly to the database.

\section{Motivating and familiarizing children to answer the daily diary}

In order to motivate young children to use the mobile application and to answer the questions, we conceived the idea of developing a fairy-tale character as a way of bringing the diary method closer to the world of young children. The fairy-tale character would send children messages ("post”) and 
ask them about their experiences. We started by creating the fairy-tale character to whom we gave an invented gender-neutral name Illi. An occupational therapy student gave Illi a voice and another one developed the character visually and drew pictures of Illi in different situations. We asked a few children for feedback on different versions of Illi, and the one that was reported as most attractive was chosen. The voices and pictures were installed in the application. To familiarize the children with the Illi as a character and with the idea of daily emotions we invented a story about Illi, which we made available both in paper form and as a file installed in the smartphone. The story was spoken and included illustrations of Illi in different situations and in different moods. Illi was introduced as a character who is interested in children's lives and regards their opinions and feelings as important and worth studying (see Appendix 1). The story was also located on the project web-site in special pages dedicated to Illi. These pages also included a song by Illi that the child could listen to if he/she wanted to.

Ethical issues. We were aware that there are a number of ethical issues involved in studying children (Einarsdóttir 2007; Morrow 2005). The issue of the asymmetry in between adult researchers and children needed to be kept in mind and reflected on throughout the research process (Clark 2005; Morrow 2005). Special attention was given also to the ethical issues involved in studying families and children. The families and children were recruited on a voluntary basis, and both the children and their parents were asked to give their informed consent. The children were asked to give their informed consent orally and the adults in writing. Participants were informed that they can discontinue their participation in the study at any point. In the case of the Illi study, children seemed to be immediately motivated to familiarize themselves with the smartphone and the pilot test questions. The second author met 15 of the children and a research assistant met the remaining 17 of the children, in order to explain and demonstrate the procedure to the children and their parents/day care personnel in detail. At the same time, they were able to ascertain the children's willingness to participate in the Illi study and how well the children were able to reflect 
on their emotions and report them as requested in the application.

Certain, specific issues have to be taken into account when using a diary methodology in studying children and families, and researchers have to be reflective and critically aware of these throughout the research process (Morrow 2005; Punch 2002). As the diary method requires special involvement from the participants, their wellbeing during a diary study has to be carefully considered. Special emphasis was placed on the usability of the electronic diary method so as not to burden the children, parents or day-care staff. Studying the perspectives of different family members in the same study may present ethical challenges; for example, the child may talk about something that her or his parents consider problematic. In researching children, in general, adults act as gate-keepers of their children's voices (Morrow 2005; Powell and Smith 2009). Because the parent-child relationship is underpinned by ideas of loyalty, trust and attachment, parents may see their child's participation in research as threatening this bond, especially in challenging family situations (see Pösö 2008). This phenomenon may be attenuated by informing the participants well beforehand and also by taking the parents' views into account in their own. In our study, the ethical dilemma of children answering questions was related to the possible presence and guidance of adults when the child was answering, although adults were requested to let the child answer by him or herself.

Feedback questions. Feedback on their participation in the diary study were collected from the children, parents and day care personnel via short questionnaires, which were mailed to homes and day care centers. The feedback questionnaire for homes included questions for both adults and to children. Both the mother and father could fill in the questionnaire especially if the parents lived in different households. Parents were requested to ask their children about experiences and report their answers on the form as well. The open-ended questions were as follows: "What did you find challenging in participating in the study? What was nice/worked well? Does your child/children have a message or greetings to send to Illi? If so, what?” At the day care centers, each 
participating day care group received one form on which all of the personnel who participated in the study could report their experiences and observations. The open-ended questions were as follows: "From the perspective of the personnel, what was challenging in participating the study? What was nicest/worked well from the perspective of the personnel? How did children and parents experience participating in the mobile diary study?”

\section{Statistical analyses}

The diary data analyses were performed using multilevel modeling. The child was used as a clustering variable. To determine what proportion of the variance in the children's moods as reported by either adults (either parent or a member of the day care personnel) or the children themselves was due to differences between individuals (between-level variation) and what due to differences reported by each individual on different days (within-level variation), intra-class correlations (ICCs) and the variance estimates at the between- and within-levels were calculated. ICCs were calculated for 10 variables: 5 moods (happy, angry, sad, worried, tired) evaluated by adults and the same 5 moods evaluated by children themselves. The closer the ICC is to one, the greater the variance between individuals in a particular mood (i.e., between-level variation).

Conversely, the closer the ICC is to zero, the greater the daily variation in a particular mood (i.e., within-level variation). A one-tailed test of significance was used (H0: between-individuals’ variance is zero; H1: between-individuals’ variance is larger than zero).

The degree of congruence between children's self-evaluated moods and evaluations of children's mood made by adults (either parent or a day care worker) was examined using betweenand within-level correlations (Bolger et al. 2003). The between-level correlation describes the degree of congruence between the average mood evaluations of the adults and children across the follow-up period. For example, a high between-correlation in happiness over the week indicates that the higher the overall happiness reported by the children was across the 7 days, the higher also was 
the overall happiness reported by the adults over the same period. In turn, the within-level correlation describes how uniformly adults and children evaluated a child's moods at a certain time point. For example, a high within-correlation in happiness indicates that the higher the level of happiness rated by the children on a particular measurement point, the higher were adults’ evaluations of happiness on the same point. The two-tailed testing of significance was used (H0: correlation coefficient is zero; H1: correlation coefficient differs from zero). Before computing the correlations, the mood variables were standardized due to differences in adults' and children's rating scales (adults 1-7, children 1-4).

All statistical analyses were performed using the Mplus statistical package (Version 7.3; Muthén and Muthén 1998-2012) with the missing data method, that is, the standard missing at random approach to missingness. This missing-data method uses all the data that are available to estimate the model without imputing data. Because the variables were skewed, the parameters of the models were estimated using maximum likelihood estimation with non-normality robust standard errors (MLR; Muthén and Muthén 1998-2012).

\section{Results}

\section{Children's moods as assessed by children and adults}

The second aim of the study was to describe children's daily moods evaluated by children and adults. Children's moods were assessed three times a day during one week both by the children themselves and adults at home and in the day care centers ( 2 X 21 assessments per child $=42$ assessments). The between-level means in the mood variables showed that the children's moods were mostly very positive: both children and adults reported that the children were generally very happy and the levels of sadness, anger and worry were generally very low. Both informants gave tiredness the second highest evaluation, as indicated by the between-level mean (see Table 3). 
Next, we studied the intra-class correlations to see to what extent individual, day-today vs inter-individual variation occurred in children's moods. The ICCs were generally low, denoting wide day-to-day variation. The ICC for happiness evaluated by children was 0.31 , indicating the presence of some individual consistency in how happy the children rated themselves.

Further, we studied whether children's self-evaluations of their moods were congruent with the evaluations of their moods by adults, both at each measurement point (within-level correlations) and over the week (between-level correlations). Five of the mood items - happiness, sadness, anger, worry and tiredness were rated by both children and adults, thereby allowing interrater comparisons at each measurement point. Both statistically significant within- and between-level correlations were found (see Table 4). The within correlations between the adults' and children's evaluations for angry mood were the strongest in the evening evaluations $(0.44 * * *)$, whereas the corresponding values in the day time and mornings were 0.13 and $0.14 *$, respectively. The within-level correlations between the adults’ and children’s evaluations for sadness were $0.32 * *$ in the evenings and $0.25 *$ in the day time. Interestingly, the within-level correlations for tiredness were nonsignificant; they were loosely linked only in the mornings $(0.15+)$. For worry, the within correlations were, however, non-significant, indicating that either the adults or children or both had difficulties in identifying worriedness or its absence. Some parents and day care staff mentioned mood evaluations in their feedback, and gave varied opinions on children's abilities to self-evaluate their emotions.

I was surprised at how well the child was able to recognize the different tones of mood and how similarly the adult's and the child's answers often were. (parent) The children were not always able to evaluate their moods, for example, despite yawning frequently during the morning, the child's answer was that he or she was not at all tired. (day care worker) 
Statistically significant between-level correlations denoting congruence between the average mood evaluations of adults and children across the follow-up period were also observed, especially in the mornings (happiness: $0.67^{* * *}$, angry mood $0.54^{*}$, sadness $0.93^{* *}$ and tiredness $0.62^{* * *}$ ). Of the mood items, statistically significant between-level correlations at all three measurement points were only found for tiredness.

Insert Table 4 about here

\section{Children's and adults' experiences of using the mobile diary}

Third, we were interested in the experiences of children, parents and day care personnel in participating in the mobile diary study. Therefore, we made a content analysis of the written feedback gathered from parents and day care personnel (adults were also asked to give feedback on behalf of the children). The main findings on the strengths and weaknesses of the method, from the perspectives of parents, day care personnel and children, are summarized in Table 5. The smartphone application was easy to use and the questions were clear. For children, using a smartphone was exciting, and the fairy-tale character Illi made participating in the study a fascinating experience. The children liked Illi very much and liked answering Illi’s messages:

He liked the whole idea very much. He looked forward to it. (parent)

The child felt that Illi figure was nice and liked answering Illi's questions. (parent) Answering was easy for the children and usually presented no problems or challenges. As the messages came at a regular rate and on time, it was mostly easy to remember to answer. Both parents and day care personnel felt that the smartphone was handy as a research tool, easier and more convenient than filling in paper questionnaires.

Much better to do research with mobile phones than with pencil and paper. (day care worker)

A mobile phone is an easy and nice tool. (parent) 
Receiving messages from Illi was a pleasant and looked-forward-to event in many participating families. Parents reported that family members were happy to gather together to listen to Illi’s messages. Many parents found it interesting and instructive to reflect on their own behavior and daily family life.

The questions made us ponder how balanced our family life is and how it is going. (parent)

(It was best) when we got together to answer Illi's questions, the whole family waited for Illi's questions. (parent)

Some challenges and weaknesses were also reported. Although the mobile phone was generally experienced as easy to use, many adults found it difficult to write their open-ended answers because of the small keyboard: 'To answer the open questions with "big fingers" is difficult‘ (day care worker).

There were also some criticisms of the diary questions. The daily repetition of the same questions started to frustrate and bore some of the participants by the end of the study week:

The same questions every day are starting to bore the child. (parent) Have a nice summer Illi! Every now and then answering was boring. It was difficult to answer questions by speaking - I could not always come up with an answer. Others were easy. Illi was nice. (boy, 6 years)

Some children, usually the older ones, would have been able to respond to the questions quicker than in the time allowed. The mood questions in particular could have been asked and responded to at a faster rate (especially towards the end of the week). The children had to answer to the questions by speaking, but some of the children (those who were already able to write) would have preferred writing. Although the families had possibilities to affect the time of answering, only a few did so. Hence, it became apparent that the answering times did not always fit in with the family's timetable. Some complained about receiving the questions too early in the 
morning (also on days when the child went to day care in the evening). Sometimes, during the busy times of the day, the participants might forget to respond. Some adults, especially day care personnel, thought that the presence of adults might have affected the children's answers.

The fact that the adult was present nearby and listening while the child answered seemed to affect the answers (the child might for example not say anything negative, only positive things). We also tried (if the child coped well with the mobile phone) to let the child answer alone in the office. On the other hand some children wanted the adult to be present. (day care worker)

In coding and analyzing the data, the possible effect of the adult on the children's answers was taken into account. Some parents, although very seldom, whispered what to answer to the child. We discarded these answers.

\section{Discussion}

In this study, we reported findings on a mobile diary study among young children who have not yet learned to read and write. We developed a mobile application in which children were drawn into the study by a fairy-tale character called Illi, who sent messages to the children. Children $(N=32)$ and their carers participated in the study by answering Illi’s questions via a smartphone. A specific aim of the study was to develop a method suited to young, pre-literate children. Further, the method needed to be sensitive to fluctuation in the moods and daily rhythms of young children whose everyday lives were spent in two different settings (home, day care) and indirectly affected by parental working time patterns (regular day work or nonstandard hours).

Our key outcome is that the mobile diary method is well suited to the study of young children's daily lives. First, the data gathered via the diary procedure were reliable and of a good quality. Besides the participants’ strong motivation to answer, the reminders issued by Illi resulted to a high response rate and a low proportion of missing values. Missing data were usually from only 
of single answering occasions; falling to answer for a whole day was rare. Further, contrary to the general assumptions the reliability of the young children's responses was satisfactory. The statistically significant within- and between-level correlations between the adults' and children's evaluations of the children's moods showed that children understood and evaluated their moods in much the same way that adults did. Our results also support the theoretical and epistemological principles of valuing children's ability to produce knowledge about their everyday lives and respecting their capacity to participate in research (see Morrow 2005; Punch 2002).

Second, our aim was to obtain information on children’s daily moods, activities and transitions between the home and day care settings. The choice of procedure where the children carried mobile phones with them and their location in either their home or day care center established by the first question worked well. Our results showed that the mobile diary was easy to integrate into the daily lives of families even where parents had irregular working time patterns and children's care times and homes varied. Our experiences are in line with those of Plowman and Stevenson (2012), who also found mobile phones suitable for studying daily family life.

Third, we were surprised that the children, and also many adults, were fascinated by Illi. There seemed to be some magic in the combination of Illi and the smartphone. For the youngest children, in particular, Illi was very real, like a friend. The children were able to use the smartphones and the application, and thus the method was highly appropriate for its purpose. Most importantly, the children were motivated and engaged to participate throughout the week. Parents noticed their children's enthusiasm and were supportive of the study. None of the 32 children or their parents dropped out during the diary week. The adult participants did not report feeling burdened, as has typically been the case among participants in paper and pencil studies of young children’s daily lives (Lämsä et al. 2013). The amount of negative feedback was low.

Our study protocol and design has a few limitations that should be taken into account in generalizing the findings. First, owing to the small sample size $(\mathrm{N}=32)$, our study suffered from 
low statistical power. However, the close equality in numbers between the two groups of participants enabled comparisons. Furthermore, the small sample size excluded the use of more complex statistical analyses. We did not, for example, analyze whether the interrater congruence between children and adults in the mood evaluations was dependent on the adult rater (i.e., mother, father, day care worker) or place (i.e., home, day care). In this study we only took into account the timing of the answers (morning, day time, evening). We will report on interactional effects of these kinds in future publications.

Second, the Illi method had a few limitations that might have weakened its reliability. These should be addressed when developing the method further. The presence of adults and other children during the target child's answering time might have affected some of the children's answers. Our methodological and ethical solution was to exclude from the analysis all answers in which we heard an adult guiding (speaking, whispering) the child in what to say. Another concern is the so called instrument effect, which means that the instrument itself may affect the content of answers. Because they felt so fond of Illi, some children started reporting matters to Illi that were unrelated to the questions asked the question. As a result, some of the answers to Illi's questions were rather short. Some children were also unwilling to talk about negative moments. Further, on the basis of the children's answers and the feedback sheets the children also created play and drawings in which Illi was included. This can be interpreted as a sign of the kind of involvement and motivation typical of young children.

Although diary reporting using a mobile application is much handier than traditional diary reporting, it nevertheless consumes time and energy. After the first few days, enthusiasm wanes and participants start becoming bored with the questions. As children are quick to learn, one way to increase motivation might be to ask the questions at a faster rate and vary them in form. On the other hand, maintaining the same question order and content could increase children's sense of competence as they come to know how to proceed. Finally, ICT and statistical expertise are needed 
in order to fully take advantage of the multiple possibilities for the collection and analysis of data afforded by the mobile diary method. All these limitations considered, this study showed that the mobile diary opens up new possibilities for the study of young children’s daily lives in multiple contexts and across different transitions.

Acknowledgements. We are grateful to students Heini Kylliäinen, Sanna Nykänen, Teemu Ahonen and Pasi Pakarinen for their important contribution to the development of the character Illi and the mobile application.

\section{References}

Bolger, N., Davis, A., \& Rafaeli, E. (2003). Diary methods: Capturing life as it is lived. Annual Review of Psychology, 54, 579-616.

Clark, A. (2005). Listening to and involving young children: A review of research and practice. Early Child Development and Care, 175, 489-505.

Connelly, M. \& Bickel, J. (2011). An electronic daily diary process study of stress and health behavior triggers of primary headaches in children. Journal of Pediatric Psychology. Advance online publication. doi:10.1093/jpepsy/jsr017.

Cremin, H. \& Slatter, B. (2004). Is it possible to access the 'voice' of pre-school children? Results of a research project in a pre-school setting. Educational Studies, 30, 457-470.

Darbyshire, P., MacDougall, C. \& Schiller, W. (2005). Multiple methods in qualitative research with children: more insight or just more? Qualitative Research, 5, 417-436.

Delle Fave, A., \& Massimini, F. (2004). Parenthood and the quality of experience in daily life: A longitudinal study. Social Indicators Research, 67, 75-106.

Einarsdóttir, J. (2007). Research with children: Methodological and ethical challenges. European Early Childhood Education Research Journal, 15, 197-211. 
Finnish Ministry of Social Affairs and Health. (2013). Child and family policy in Finland. Helsinki: Finnish Ministry of Social Affairs and Health.

Gallacher, L.-A. \& Gallagher, M. (2008). Methodological immaturity in childhood research? Thinking through 'participatory methods'. Childhood, 15, 499-515.

Gassman-Pines, A. (2011). Low-income mothers’ nighttime and weekend work: Daily associations with child behavior, mother-child interactions, and mood. Family Relations, 60, 15-29.

Intille, S. S. (2012). Emerging technology for studying daily life. In M. R. Mehl \& T. S. Conner (Eds.), Handbook of research methods for studying daily life (pp. 267-282). New York: The Quilford Press

Jordan, D. (2008). The ecology of infant and toddler care during nonstandard hours in licenced childcare centers. Doctoral dissertation. Michigan State University.

Halfon, S. \& Friendly, M. (2015). Work around the clock. A snaphot of non-standard hours child care in Canada. Childcare Resource and Research Unit Publication. Occasional paper 29.

Hsueh, J.A. \& Yoshikawa, H. (2007). Working nonstandard schedules and variable shifts in lowincome families: Associations with parental psychological well-being, family functioning, and child well-being. Developmental Psychology, 43, 620-632.

Larson, R. (1989). Beeping children and adolescents: A method for studying time use and daily experiences. Journal of Youth and Adolescence, 18, 511-530.

Larson, R.W., \& Almeida, D.M. (1999). Emotional transmission in the daily lives of families: A new paradigm for studying family process. Journal of Marriage and the Family, 61, 5-20.

Laurenceau, J., \& Bolger, N. (2005). Using diary methods to study marital and family processes. Journal of Family Psychology, 19, 86-97.

Li, J., Johnson, S., Han, W-J., Andrews, S., Kendall, G., Strazdins, L., \& Dockry, A. (2014). Parents’ nonstandard work schedules and child well-being: A critical review of the literature. The Journal of Primary Prevention, 35, 1-21. 
Lämsä, T., Rönkä, A., Poikonen, P.-L., \& Malinen, K. (2012). The child diary as a research tool. Early Child Development and Care, 182, 469-486.

Malinen, K., Rönkä, A., \& Sevon, E. (2015). Mobile diary methods in studying daily family life. In Zheng Yan (Eds.) Encyclopedia of mobile phone behavior (p. 372-382). Hershey, PA, USA: IGI Global.

Malinen, K., Rönkä, A., Tolvanen, A., Sevón, E., \& Jokinen, K. (2015). A Mobile diary method for studying children's and adolescents' emotions: A pilot study. Social Inquiry into Well-being, 1, 51-60.

Matthews, M., Doherty, G., Sharry, J., \& Fitzpatrick, C. (2008). Mobile phone mood charting for adolescents. British Journal of Guidance and Counselling, 36, 113-129.

Mills, M. \& Täht, K. (2010). Non-standard work schedules and partnership quality: Quantitative and qualitative findings. Journal of Marriage and Family, 72, 860-875.

Morrow, V. (2005). Ethical issues in collaborative research with children. In A. Farrell, (Eds.) Ethical research with children (pp. 150-165). Maidenhead: Open University Press.

Muthén, L. K., \& Muthén, B. (1998-2012). Mplus user’s guide (7th ed.). Los Angeles: Authors.

Perrez, M., Schoebi, D., \& Wilhelm, P. (2000). How to assess social regulation of stress and emotions in daily family life? A computer-assisted family self-monitoring system (FASEMC). Clinical Psychology and Psychotherapy, 7, 326-339.

Plowman, L., \& Stevenson, O. (2012). Using mobile phone diaries to explore children’s everyday lives. Childhood, 4, 539-553.

Powell, M. \& Smith, A. (2009). Children’s participation rights in research. Childhood, 16, 124-142.

Presser, H. B. (2003). Working in a 24/7 economy: Challenges for American families. New York, NY: Russell Sage Foundation.

Punch, S. (2002). Research with children. The same or different from research with adults? Childhood, 9, 321-341. 
Pösö, T. (2008). Kiistanalaiset perhesuhteet ja tutkimisen moraali [Disputable family relationships and the morals in studying]. In E. Sevón \& M. Notko (Eds.) Perhesuhteet puntarissa [Considering family relationships] (pp. 93-107). Helsinki: Gaudeamus.

Rönkä, A., Malinen, K., Jokinen, K., \& Häkkinen, S. (2015). A Mobile-assisted working model for supporting daily family life: A Pilot study. The Family Journal, 23, 180-189.

Rönkä, A., Malinen, K., Kinnunen, U., Tolvanen, A., \& Lämsä, T. (2010). Capturing daily family dynamics via text messages: development of the mobile diary. Community, Work \& Family, $13,5-21$.

Sevón, E., Malinen, K., \& Rönkä, A. (2014). Daily wellbeing in families with young children: A harmonious and a disharmonious week. Journal of Family Studies, 20, 221-238.

Statham, J., \& Mooney, A. (2003). Around the clock: Childcare services at atypical times. Bristol: Policy Press

Strazdins, L., Clements, M. S., Korda, R. J., Broom, D. H., \& D’Souza, R. M. (2006). Unsociable work? Nonstandard work schedules, family relationships, and children’s well-being. Journal of Marriage and Family, 68, 394-410.

Strazdins, L., Korda, R. J., Lim, L., Broom, D. H., \& D’Souza, R. M. (2004). Around-the-clock: parent work schedules and children's well-being in a 24-h economy. Social Science \& Medicine, 59, 1517-1527.

Säkkinen, S., \& Kuoppala, T. (2011). Lasten päivähoito 2010 [Children's daycare 2010].

Tilastoraportti [Statistical report] 46. Terveyden ja hyvinvoinnin laitos [National Institute for Health and Welfare].

Verhoef, M., Tammelin, M., May, V., Rönkä, A., \& Roeters, A. (2015). Child care and parental work schedules: A comparison between Finnish, British and Dutch parents. Community, work and family (online) DOI:10.1080/13668803.2015.1024609 
Whalen, C. K., Henker, B., Jamner, L. D., Ishikawa, S. S., Floro, J. N., Swindle, R., Perwien, A. R., \& Johnston, J. A. (2006a). Toward mapping daily challenges of living with ADHD: Maternal and child perspectives using electronic diaries. Journal of Abnormal Child Psychology, 34, 115-130.

Whalen, C.K., Henker, B., Ishikawa, S.S., Jamner, L. D., Floro, J. N., Johnston, J. A., \& Swindle, R. (2006b). An electronic diary study of contextual triggers and ADHD: Get ready, get set, get mad. Journal of American Academy of Child and Adolescent Psychiatry, 45, 166-174. 